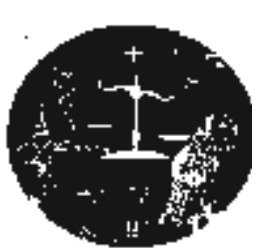

\title{
Análise dos leilões de petróleo e gás natural: o MODELO DE CONCESSÃO E PARTILHA DE PRODUÇÃo
}

\author{
DOI: $10.12957 /$ synthesis.2015.25828
}

\section{Mônica Maria Apolinário Teixeira *}

\begin{abstract}
Resumo: O presente artigo tem por objetivo analisar o desempenho e os resultados dos leilões de blocos exploratórios de petróleo à luz da teoria dos leilões e das mudanças do marco regulatório que vêm ocorrendo nos últimos anos, bem como o melhor desenho de leilão que se aplica para tratar dos problemas assinalados, levando-se em consideração as assimetrias informacionais. A avaliação sobre o desenho de leilão adotado para a oferta de blocos exploratórios é fundamental para entender a dinâmica do setor de petróleo e os problemas enfrentados por ele. Através da análise das rodadas de licitações promovidas pela ANP, conclui-se que o modelo de leilão adotado favorece o problema da "maldição do vencedor" e que o regime de partilha de produção apresenta várias falhas na sua formulação, pois tem regras complexas e não favorece a concorrência entre os participantes. Ao final, são apresentadas algumas sugestões de política econômica, incluindo algumas características dos leilões aplicáveis ao caso brasileiro, bem como uma abordagem introdutória da importância da utilização de experimentos econômicos em ambientes controlados.

Palavras-chave: Modelos de Concessão e Partilha de Produção. Rodadas de Licitação. Teoria dos Leilões. Maldição do Vencedor e Economia Experimental.
\end{abstract}

\section{Analysis of oil and gas auctions: model concession and production sharing}

Abstract: The major objective of this paper was to analyze the performance and results of auctions for oil exploration blocks in light of the theory of auctions and changes in the regulatory framework that has been occurring in recent years, as well as the best auction design that applies to treat the problems identified, taking into account informational asymmetries. The evaluation of the auction design assumed offering exploration blocks is fundamental to understand the dynamics of the oil industry and its correlated problems. The analysis of the bidding rounds organized by the ANP concluded that the auction model assumed favoring the problem of winner's curse and the share production model has several flaws in its formulation. It has complex rules and does not promote competition among participants. Finally, some suggestions of economic policy are presented, including some auction specifications applied to the Brazilian case, as well as an introductory approach discussing the importance of using economic experiments in controlled environments.

Keywords: Concession and Share Production Models. Bidding Rounds. Auction Theory. Winner's Curse and Experimental Economics.

\footnotetext{
* Mestre em Ciências Econômicas, Universidade do Estado do Rio de Janeiro, e-mail: mmateixeira@ yahoo.com.br, currículo lattes:
} http://lattes.cnpq.br/4110723936726229.

\section{INTRODUÇÃo}

Nos últimos anos, a indústria petrolífera nacional vem atravessando uma nova fase na sua história, sendo representada pela promulgação de duas leis importantes.
A Lei n ${ }^{\circ}$ 9.478/97, conhecida como "Lei do Petróleo", estabeleceu um novo desenho institucional na indústria do petróleo nacional, através da criação da Agência Nacional do Petróleo (ANP) e das modificações 
efetuadas no ambiente regulatório, com a inserção de novos agentes e suas atribuições, e constituiu o regime de concessão para contratar empresas públicas ou privadas para o exercício das atividades de exploração e produção de petróleo e gás natural no Brasil, possibilitando a realização de leilões de blocos exploratórios.

A descoberta de áreas de exploração na camada do pré-sal trouxe perspectivas positivas em relação ao potencial de produção nestas regiões. Assim, em 2009, este novo contexto somado à elevação do preço internacional do petróleo criou um cenário econômico que desencadeou um entendimento político com a necessidade de se criar novas regras para melhor alocação destes recursos. Desse modo, foi promulgada a Lei $n^{\circ} 12.351 / 2010$, que permitiu a exploração e a futura produção na camada pré-sal, sob o regime de partilha de produção. O modelo escolhido teve como objetivo garantir maior parcela dos recursos para a União como, também, o maior controle sobre as atividades do setor.

Com a introdução do modelo de partilha de produção passaram a coexistir dois regimes regulatórios (Lei $\mathrm{n}^{\circ}$ 9.478/97 e Lei no 12.351/10) no setor de petróleo e gás, cada um com suas especificidades e estrutura de incentivos, suscitando vários questionamentos, que serão mais bem compreendidos e avaliados através do arcabouço da teoria dos leilões, pois na presença de um cenário de grandes incertezas e informação assimétrica, estudos teóricos e empíricos de desenho de mecanismos de leilões poderão contribuir para encontrar novas alternativas e soluções para os problemas decorrentes desta escolha política. Ademais, a economia experimental através da possibilidade de testar desenhos alternativos de políticas, corrigindo os seus erros antes de implementálos, auxilia na condução destas questões econômicas de tal forma a gerar maior eficiência ao setor de petróleo.

Desde 1999, a ANP vem realizando rodadas de licitações para exploração, desenvolvimento e produção de petróleo e gás natural. A agência já realizou doze rodadas, pelo regime de concessão, que contribuíram para o progresso da indústria petrolífera nacional.

Em maio de 2013, o governo brasileiro realizou o primeiro leilão sob o regime de partilha de produção, 0 leilão da bacia de Libra, que despertou grandes expectativas devido a sua potencialidade, porém o resultado não foi o esperado, pois o novo modelo não se mostrou capaz de gerar concorrência e atrair grandes empresas internacionais. Além disso, o governo entregou as reservas pelo valor mínimo determinado por lei. As inconsistências presentes no desenho de leilão, formado por regras complexas, faz surgir a necessidade de que ele seja revisto. Assim, destacam-se a importância da economia experimental e a implementação de alguns tipos de leilões para ajudar a mitigar os problemas do setor de petróleo delineando cenários mais claros.

Assim, objetivou-se aqui analisar os leilões realizados pela ANP, em especial o leilão da bacia de Libra, sob o instrumental da teoria dos leilões, avaliando a possibilidade de se utilizar experimentos econômicos em laboratório para resolver o problema da "maldição do vencedor", que ocorre quando os vencedores de leilões sistematicamente adquirem objetos por um valor superior ao seu valor real. Para tanto, o presente trabalho está dividido em quatro seções, além desta introdução e da conclusão.

A segunda seção analisa os principais conceitos e aspectos relevantes da teoria dos leilões. Além disso, apresenta um panorama teórico da economia experimental enfatizando a importância do uso de experimentos econômicos. A terceira seção mostra as principais características do modelo de concessão e discute as doze rodadas de licitações. A quarta seção apresenta o regime de partilha de produção e avalia os resultados do primeiro leilão na área do polígono do pré-sal - na bacia de Libra. Por fim, a quinta seção analisa os resultados obtidos a partir do presente estudo, propondo algumas sugestões de políticas econômicas, incluindo a possibilidade do uso de leilões experimentais para alcançar resultados mais eficientes.

\section{Principais Conceitos da Teoria dos Leilões e a ECONOMIA EXPERIMENTAL}

\subsection{TEORIA DE LELLÕES}

Embora o estudo acadêmico de leilões seja recente, 
a teoria dos leilões é uma das teorias econômicas modernas mais bem-sucedidas, tendo destaque no cenário econômico atual, de modo que a sua análise tem sido amplamente abordada em diversos trabalhos teóricos e empíricos. Vários países conduzem experimentos com a finalidade de estudar equilíbrios provenientes de diferentes regras de leilões. Conforme posto por Menezes e Monteiro (2004), o sucesso da teoria é decorrente da sua capacidade de fornecer instrumentos para a avaliação de políticas práticas, fazendo com que este mecanismo tenha aplicações em numerosos mercados. Como exemplos, temos leilões para compras públicas, leilões para privatizações, leilões de espectro para emissão de sinais de televisão e comunicação via celular e leilões de blocos exploratórios de petróleo e gás natural.

De acordo com Klemperer (2001), o que realmente importa no desenho de um leilão são as mesmas questões destacadas pelas políticas de concorrência: i) desencorajar conluio, ou seja, desestimular a conduta anticompetitiva; ii) impedir a prática predatória; iii) coibir o comportamento de produzir barreiras à entrada de novos participantes no certame; e iv) combater a concentração excessiva de poder de mercado. Tais comportamentos produzem resultados economicamente ineficientes, gerando prejuízo para os licitantes. Do mesmo modo, do ponto de vista das políticas públicas, o principal objetivo é desenhar um modelo de leilão capaz de reduzir estes problemas. Por conseguinte, algumas questões precisam ser abordadas, pois muitas vezes são omitidas ao elaborar leilões. São elas:

1) O leilão promove eficientemente a alocação do objeto leiloado?

2) A estrutura e as regras do leilão incentivam a competição?

3) O leilão tem a capacidade de impulsionar uma competição dinâmica, impedindo barreiras à entrada e possibilitando a inserção de novos participantes?

4) O leilão estimula a participação de empresas pequenas?

Klemperer (2004 apud MATTOS, 2008) definiu que os principais tipos de leilões para a alocação de um único objeto são: i) leilão de lances ascendentes ou abertos, oral ou inglês: sob a supervisão de um leiloeiro, os participantes realizam lances no certame, até o momento em que um dos lances não seja mais coberto por outros participantes, ou seja, o preço é aumentado pelos jogadores somente até um único continuar no certame e ser o vencedor do leilão. Na ausência de colusão, a estratégia ótima de cada jogador será prosseguir no certame realizando alguns lances pelo objeto até que o último lance tenha um valor igual ou superior ao valor conferido ao bem;

ii) leilão de lances descendentes ou holandês: é o oposto do leilão ascendente, neste caso o leiloeiro começa com um preço alto e vai fazendo continuamente reduções do valor até o momento em que um dos jogadores aceita a proposta, sendo assim, nenhum outro participante poderá cobrir a oferta;

iii) leilão selado de primeiro preço: cada participante coloca o seu lance dentro de um envelope lacrado. $\mathrm{O}$ participante dá um único lance sem ter conhecimento da oferta dos outros competidores, assim vence o leilão aquele que oferecer o maior lance, pagando o preço que propôs após o leiloeiro abrir simultaneamente os envelopes. Desse modo, o jogador tem o incentivo de aumentar a sua oferta para ter a oportunidade de ser o vencedor do leilão; por outro lado, o participante tem o incentivo de diminuir o seu lance para pagar um preço mais baixo no caso de vencer o leilão; assim os participantes tendem a fazer lances inferiores ao valor concedido ao objeto;

iv) leilão selado de segundo preço ou leilão de Vickrey: é praticamente igual ao leilão selado de primeiro preço, exceto pelo fato de que, embora o participante vença o leilão com o maior lance, pagará o preço igual ao valor do segundo maior lance. A estratégia dominante adotada pelos jogadores é sempre realizar um lance igual ao valor atribuído ao bem, pois o valor a ser pago independe do seu lance.

Conhecida a tipologia dos leilões, cabe enfatizar que o teorema da equivalência de receitas (TER) é o principal da teoria dos leilões, podendo ser considerado a base desta teoria. De acordo com o teorema, todos os tipos básicos de leilões produzem a mesma receita esperada, sob determinadas condições de igualdade entre os 
licitantes. Segundo Cramton (2006), as condições para que o TER seja válido são: i) o objeto a ser leiloado é único; ii) os participantes têm valores privados e independentes, sendo neutros em relação ao risco; iii) o número de jogadores deve ser independente do tipo de leilão, não havendo colusão; e iv) simetria entre os participantes. Na realidade, essas hipóteses não são factíveis, pois várias questões devem ser levadas em consideração, tais como: o valor atribuído a um bem, por parte de um licitante, considera as estimativas dos outros participantes e os jogadores se importam com os riscos; existem diferenças ex-ante entre os participantes, e mitigar os problemas de colusão estabelece um ponto relevante.

No caso brasileiro, no que diz respeito às licitações de áreas de exploração de petróleo e gás natural, em relação ao objetivo do leiloeiro (o governo), o desenho de leilão mais apropriado é aquele que se produz com mais eficiência ou o que promove maior receita? Apesar de ambos os objetivos convergirem, presume-se que a principal finalidade seja a eficiência.

A teoria dos leilões sinaliza a existência de um tradeoff de objetivos entre a eficiência econômica e a renda do leiloeiro, que tendem a convergir quando o desenho do leilão é bem feito. Os licitantes que atribuem maior valor ao bem leiloado, provavelmente, são os mais capazes de gerar valor. Quando o poder de mercado é incorporado à análise, compromete a coincidência de objetivos entre maior geração de rendimentos e eficiência, pois as maiores ofertas realizadas pelo detentor do poder de mercado podem indicar apenas a sua capacidade de sustentar preços elevados, ou a sua vontade de manter poder de mercado, e não a sua verdadeira eficiência produtiva. Assim como o conluio tem a capacidade de aumentar o poder de mercado dos seus membros, a presença de colusão também pode propiciar algumas distorções nos arranjos e resultados dos leilões. Em especial, nos leilões de petróleo e gás natural, observa-se a grande propensão de colusão devido à dimensão das empresas participantes, podendo desencadear um número reduzido de licitantes em cada rodada de licitação de blocos exploratórios.

O TER também se aplica a leilões com valores privados e valores comuns em que os sinais entre os participantes são independentes entre si. Os leilões com valores privados dependem da informação e da apreciação individual do objeto, ou seja, cada player tem o conhecimento exato de quanto ele valora o objeto, sendo esta informação privada para ele. Dessa forma, o player não irá mudar a sua estimativa do valor do objeto se apreender sinais (ou lances) de outros participantes. Os leilões com valores comuns dependem do valor real do objeto, idêntico para todos os players, porém estes possuem diferentes informações privadas sobre esse valor.

Cramton (2006) ressalta que os leilões de petróleo e gás natural são exemplos típicos de leilões de valores comuns, pois a quantidade e os preços internacionais serão os mesmos independentemente do vencedor do certame. Vale destacar que o valor da concessão de exploração de uma área de petróleo ou gás depende dos sinais geológicos que cada participante possui sobre aquele campo. Sendo assim, os players poderão modificar as suas estimativas em relação ao valor do objeto ao adquirir conhecimento sobre os "sinais" ou lances de outros participantes.

Um tema frequentemente abordado na teoria dos leilões é a assimetria de informação, pois a sua presença em um ambiente de leilões acentua o risco da "maldição do vencedor". Tal situação é caracterizada pela tendência de o vencedor do leilão ter realizado um lance acima do valor real do objeto. Se todos os outros participantes fizeram ofertas menores e seus valores são comuns, possivelmente o competidor superestimou o valor do objeto e acabou pagando por este mais do que de fato vale - ou pensou que valesse. A situação se agrava quanto maior for a assimetria recíproca de informações e/ou se houver um ou mais players notoriamente com mais informações do que outros participantes. Desse modo, o leilão selado de primeiro preço é mais vulnerável ao problema da "maldição do vencedor", pois os participantes não podem rever seus lances em face dos lances dos outros. Já o leilão ascendente é menos vulnerável, pois os participantes podem revisar suas ofertas com base no aprendizado gerado pelos lances dos outros. 
Roth (1995) aborda que o fenômeno da "maldição do vencedor" no contexto de leilões de petróleo apareceu na literatura econômica através de um artigo de Capen, Clapp e Campbell (1971), três engenheiros de petróleo que trabalhavam na companhia americana Atlantic Richfield. Eles alegaram que as empresas de petróleo tinham baixa taxa de retorno nos leilões de blocos exploratórios, e que isso se devia ao fato de o vencedor do leilão ser normalmente o que tem maior estimativa do valor do petróleo recuperável, e que a estimativa mais elevada é muitas vezes uma superestimativa.

Bazerman e Samuelson (1983 apud ROTH, 1995) foram os primeiros a realizar um experimento controlado para analisar a ocorrência da "maldição do vencedor" em um ambiente de laboratório. Segundo os autores, este fenômeno é causado por dois fatores importantes: o grau de incerteza em relação ao valor do objeto leiloado, pois quanto maior o valor atribuído ao objeto, maior será a variância das suas estimativas e maior o número de participantes do leilão, visto que um acréscimo no número de participantes provoca o aumento da variância das estimativas e das ofertas do objeto a ser leiloado (VANZAN, 2004, p. 22).

Hendricks e Porter (1988 apud BRAGANÇA; SALGADO, 2012), avaliando o caso americano, fizeram testes empíricos em alguns modelos de equilíbrio em leilões para bens públicos com informação assimétrica, utilizando informações ex-post sobre áreas de exploração de petróleo. Através da análise de dados históricos, os autores concluíram que as empresas donas de áreas adjacentes possuíam melhores informações sobre o valor da área em comparação com as empresas que não estavam próximas destas, pois apresentavam conhecimento do terreno e já atuavam no mesmo território, podendo assim coordenar suas ofertas no leilão. Hendricks, Pinkse e Porter (2003 apud Bragança e Salgado, 2012) também contribuíram para esta questão, chegando à conclusão de que os participantes dos leilões de exploração de petróleo estavam cientes da existência de "maldição do vencedor" e realizavam seus lances de acordo com esta informação.

Acrescenta-se também o fato de que os leilões de petróleo e gás natural no Brasil são influenciados negativamente pelo problema da "maldição do vencedor", pois possuem como características valores comuns e acentuada assimetria de informação entre os participantes dos leilões. Além disso, a existência de um player nacional, no caso a Petrobras, com grande vantagem informacional e poder de mercado, deixa os problemas assinalados ainda mais críticos.

Diante do exposto, temos que, para solucionar os problemas relativos à "maldição do vencedor", torna-se conveniente aplicar leilões híbridos. Klemperer (2004 apud MATTOS, 2008, p. 80) propôs o leilão angloholandês, que é realizado em duas etapas, sendo um híbrido de leilão ascendente em um primeiro estágio e leilão selado (por exemplo, no caso de restarem apenas dois compradores) em um segundo estágio com uma oferta final única. Para o autor, este modelo frequentemente tem desempenho superior se comparado às formas puras dessas duas modalidades, pois consegue mesclar as características positivas de cada uma delas sem incorrer nos mesmos erros. Além disso, o modelo propicia a propagação da informação na primeira fase, dificultando práticas anticompetitivas na segunda.

Segundo Mattos (2008, p. 81), outro tipo de leilão híbrido é o clock-proxy, que também ocorre em duas fases. No primeiro estágio (clock), o procedimento é similar ao do leilão ascendente simultâneo, porém sem a possibilidade de lances em pacotes. Neste caso, os novos preços para cada objeto são anunciados pelo leiloeiro, sendo que os participantes que não tiverem de acordo saem da disputa daquele ou de outros objetos. No momento em que se atingir um vetor de preços no qual apenas sobrem dois participantes por objeto, este estágio finaliza, passando-se para o segundo estágio (proxy). Neste último, todos os participantes que permanecerem na disputa em seu objeto específico estão autorizados a realizar tanto lances individuais para cada lote como lances em pacotes de lotes, também de forma ascendente e simultânea, tendo a permissão de realizar lances por pacotes.

\subsection{ECONOMIA EXPERIMENTAL}

A economia experimental é a aplicação de métodos experimentais no estudo da teoria econômica, em um 
ambiente controlado e regido por regras específicas. Experimentos e simulações são realizados, em laboratório, para testar a validade das questões econômicas e para avaliar o comportamento dos mecanismos de mercado. Os experimentos são realizados com indivíduos, que ajudam a compreender porque os mecanismos de mercado às vezes funcionam de maneira eficiente, outras vezes falham. Ademais, certos aspectos econômicos são mais bem estudados de forma experimental. A capacidade de isolar as variáveis permite maior controle sobre cada fator relevante da investigação. Desse modo, o principal objetivo dos experimentos é gerar resultados que sejam capazes de promover modelos mais próximos da realidade.

De acordo com Roth (1995), o primeiro experimento econômico foi realizado em 1738, pelos irmãos Daniel Bernoulli e Nicholas Bernoulli, que conceberam o Paradoxo de São Petersburgo. Embora os resultados dessa investigação tenham sido descritos de maneira bastante informal, essa experiência incentivou a prática de elaborar problemas de escolha hipotéticos para conceber hipóteses sobre o comportamento individual, que tem sido utilizado com bons resultados em pesquisas mais modernas sobre experimentos em economia.

Ainda conforme o autor, a literatura sobre economia experimental pode ser dividida em três correntes. A primeira vertente foi delineada para testar teorias de escolha individual, tendo início com os estudos de Thurstone (1931 apud Roth, 1995, p. 5) sobre teoria ordinal da utilidade ao testar de forma experimental, a representação das preferências individuais na curva de indiferença e a obtenção de dados para estimar esta curva. Para realizar o experimento ele selecionou um grupo de pessoas, em que cada indivíduo deveria fazer escolhas hipotéticas entre conjuntos de determinados bens formados por chapéus e casacos, chapéus e sapatos, e sapatos e casacos. Sendo assim, concluiu que esse tipo de escolha de dados poderia ser representado adequadamente por curvas de indiferença e que era prático de estimá-los.
A publicação do livro Theory of Games and Economic Behavior de Von Neumann and Morgenstern, em 1944, sobre a teoria dos jogos, estimulou vários acadêmicos a estudar a teoria da utilidade, nos anos subsequentes. A partir de então, a teoria experimental e a teoria dos jogos têm mantido uma influência recíproca.

A segunda vertente, de estudos na área experimental, começa a partir do trabalho de Dresher e Flood (1950 apud Roth, 1995) no qual fizeram testes experimentais de algumas hipóteses da teoria dos jogos, que desencadearam a formulação do famoso dilema dos prisioneiros. Finalmente, a última vertente está relacionada a pesquisas desenvolvidas no campo da organização industrial, com foco no trabalho de Chamberlin (1948 apud Roth, 1995), em que realizou várias simulações experimentais em laboratório para testar as condições de mercado.

Além disso, Roth (1995) destaca que no final da década de 1960, as pesquisas utilizando economia experimental já possuíam bases mais sólidas e maior aceitação internacional, tendo o cuidado de testar teorias mais genéricas e definir regras claras para o ambiente experimental. A consolidação da economia experimental como parte das ciências econômicas, no sentido da formação de um corpo de estudo baseado em experimentos de laboratório, ocorreu a partir de 1980, através de publicações científicas em revistas internacionais de grande notoriedade.

Vernon Smith $(1962 ; 1964)$ apresentou em seus trabalhos como conseguiu repetir a lei da oferta e demanda em mercados competitivos. Em 2002, o referido autor foi agraciado com o Prêmio Nobel de Economia por ser o pioneiro em estudos que mostram como a economia experimental contribui para a tomada de decisão. Para tal feito, ele desenvolveu uma série de métodos experimentais, através de experimentos econômicos de forma controlada, que foram utilizados como padrão para aplicar resultados em laboratório, influenciando no comportamento dos indivíduos em diferentes tipos de leilões.

Por fim, o mais interessante da economia experimental é apresentar hipóteses alternativas a serem 
desenvolvidas, realizando testes e observando a viabilidade dos modelos. Assim, os princípios econômicos podem ser analisados de maneira eficiente, permitindo novas previsões e melhorias sobre o desenho de mecanismo original.

\section{O Regime de Concessão e os Leilões de BLOCOS EXPLORATÓRIOS}

Entre os anos de 1953 e 1997, a Petrobras teve o privilégio de exercer o monopólio das atividades relacionadas ao setor de petróleo no Brasil. Com a flexibilização do monopólio, a estatal passou a atuar no mercado como uma empresa concessionária.

A Lei do Petróleo, Lei n ${ }^{\circ} 9.478$ de 6 de agosto de 1997, inaugurou um novo marco regulatório para o setor petrolífero nacional - a implementação do regime de concessão, após quase 45 anos de monopólio na exploração e refino. Desde a promulgação da referida lei, o modelo de concessão constituía o único meio legal para o exercício das atividades de exploração, desenvolvimento e produção $(\mathrm{E} \& \mathrm{P})$ de petróleo e gás natural no Brasil. Neste regime, a União, sempre mediante licitação, contrata com empresas estatais e/ou privadas a realização das atividades de E\&P. Este modelo de exploração de petróleo é o mais antigo do mundo e atualmente é utilizado por $44 \%$ dos países (Gomes, 2009).

A referida Lei ainda dispôs sobre a política energética nacional e instituiu o Conselho Nacional de Política Energética - CNPE e a Agência Nacional do Petróleo (posteriormente, Agência Nacional do Petróleo, Gás Natural e Biocombustíveis - ANP, através do Decreto $n^{\circ} 2.455 / 1998$ ). Além disso, trouxe diversas mudanças estruturais para o setor, tais como: a abertura do mercado, a desregulamentação dos preços e os leilões de blocos exploratórios de petróleo e gás natural sob o modelo de concessão.

Tal regime de concessão foi beneficiado pela estabilidade do arcabouço regulatório e eficiência do setor petrolífero, garantidas pela ANP. Este modelo permite ao concessionário explorar as áreas ofertadas, incorrendo em todos os riscos da atividade. Após produzir petróleo ou gás natural em determinada área, ele torna-se detentor dos bens e fica responsável pelo pagamento dos tributos e cumprimento dos termos contratuais. Atualmente, só é válido para a exploração e produção de petróleo e gás natural fora da área do pré-sal ${ }^{1}$.

De acordo com essa legislação, apesar de o governo manter a titularidade das reservas de petróleo e gás existentes em território nacional, as atividades de E\&P dos hidrocarbonetos ${ }^{2}$ passam a ser exercidas sob o regime de concessão. Isso implica que os investidores contemplados pelas rodadas de licitações tornam-se proprietários do petróleo e gás natural provenientes da atividade de E\&P, isto é, o produto da lavra, em contrapartida aos compromissos e obrigações descritos em contrato, como o pagamento de participações governamentais e tributos.

É importante observar que o petróleo e o gás natural no subsolo, isto é, as reservas de hidrocarbonetos, permanecem de propriedade da União; afinal, é o produto da lavra (os volumes de petróleo e gás natural produzido) que tem sua titularidade transferida ao concessionário a partir da cabeça do poço. Recebida a titularidade, o concessionário poderá dispor livremente sobre o produto da lavra.

Em relação aos Contratos de Concessão, temos que a sua duração gira em torno de 30 a 40 anos, abrangendo duas fases: exploração e produção. A primeira fase tem por finalidade viabilizar a descoberta de jazidas, permitindo a avaliação por parte do concessionário. Durante o período de exploração deve adquirir dados, realizar estudos geológicos e geofísicos, perfurar poços e estudar a possibilidade de comercialização das descobertas de petróleo e gás natural. Já a segunda fase engloba a avaliação, o desenvolvimento e a produção de hidrocarbonetos. Esta fase começa na data de entrega da declaração de comercialidade do campo, pelo concessionário, à ANP, podendo sua duração ser reduzida ou prorrogada, de acordo com o contrato de concessão e por requerimento do concessionário ou da agência reguladora. Finalizada a fase de produção, o campo será devolvido à ANP.

$O$ presente modelo instituiu um regime fiscal específico. No caso brasileiro, o Estado, que tem a posse dos recursos minerais, através de um contrato de concessão, transfere a sua exploração a terceiros, sendo 
remunerado pelas participações especiais. Dessa forma, além dos tributos e contribuições sociais federais, estaduais e municipais, incidentes sobre todos os agentes econômicos, os concessionários são submetidos ao pagamento de participações especiais e de terceiros.

Contudo, as principais participações governamentais estabelecidas pela Lei do Petróleo são: bônus de assinatura, royalties, participação especial e pagamento pela ocupação ou retenção de área. A primeira é constituída pelo valor pago pelo licitante vencedor no ato da assinatura do contrato de concessão. A segunda corresponde a uma compensação financeira paga ao governo, pelos concessionários, devido à utilização dos recursos naturais explorados. Assim, os royalties incidem diretamente sobre o volume de petróleo e gás natural produzido. A terceira é uma compensação financeira paga de forma trimestral quando níveis substanciais de petróleo forem produzidos. Por último, temos que o pagamento da taxa pela retenção de área é realizado anualmente, por causa da utilização das reservas sob concessão, evitando que as empresas concessionárias mantenham-se de maneira estratégica em algumas áreas em que a princípio elas não têm interesse.

\subsection{Rodadas de Licitações de Petróleo REALIZADAS PELA ANP}

Antes de analisar as rodadas de licitações, convém apresentar o desenho dos leilões de petróleo e gás natural:

i) leilão selado de primeiro preço com múltiplos objetos (blocos), sendo que cada conjunto de blocos compõe um setor. Este tipo de leilão é extremamente vulnerável ao problema da maldição do vencedor, em que as empresas pagam mais do que vale o bem leiloado;

ii) leilão semi-simultâneo (simultâneo para os blocos e sequencial para os setores), ou seja, há um misto de leilão simultâneo e sequencial, no qual os lances de um participante para um conjunto de blocos pertencentes a um mesmo setor são reunidos em um único lance selado. Somente após conhecido o resultado do leilão dos lotes de um setor, abre-se o processo de apresentação dos lances para os blocos pertencentes ao setor seguinte; iii) lances em pacotes não são permitidos (para blocos diferentes); iv) o processo deve ser público e transparente, podendo ser realizados lances em consórcio, com ou sem a participação da Petrobras;

v) nas primeiras quatro rodadas (1999-2002), o bônus de assinatura ofertado pelas concessionárias deveria ser maior que o valor mínimo determinado no Edital de Licitação. Assim, o licitante vencedor era aquele que alcançasse a maior nota, sendo que $85 \%$ desta referiamse ao bônus de assinatura (Mielnik, 2014);

vi) a quinta rodada (2003) trouxe mudanças significativas para o setor, como a inclusão do Programa Exploratório Mínimo (PEM), que passou a fazer parte da oferta, juntamente com o bônus de assinatura e o compromisso de aquisição de bens e serviços de fornecedores nacionais (Conteúdo Local). O PEM é o compromisso assumido pelas empresas concessionárias de fazer investimentos mínimos na fase de exploração de petróleo;

vii) as rodadas cinco (2003) e seis (2004) foram prejudicadas pela ausência de um limite superior de conteúdo local, dificultando que as ofertas alcançassem o percentual de participação. Na sétima rodada (2005) foi restabelecido o conteúdo local, fixando-se um teto;

viii) a oitava rodada (2006) foi interrompida por decisão judicial, sendo cancelada, em 2009, pela ANP;

ix) a nona rodada (2007) gerou algumas polêmicas no cenário econômico, devido ao fato de que o CNPE (cuja função é definir o número de blocos exploratórios de petróleo que serão incluídos em uma determinada licitação) determinou a retirada de 41 blocos dos 271 que seriam ofertados no leilão. Isso, logo após a Petrobras descobrir alguns campos com grande potencial de exploração, como o de Tupi (hoje conhecido como Campo de Lula) que continha cinco bilhões de barris de petróleo e havia sido arrematado por $\mathrm{R} \$ 15$ milhões por um consórcio formado pela empresa incumbente (Petrobras, que foi a operadora ficando com 65\%), BG (25\%) e Petrogal (10\%). Esse fato desencadeou o afastamento de grandes petroleiras que atuam no mercado internacional (Mielnik, 2014).

ATabela 1 a seguir sintetiza os principais resultados da Primeira à Décima Segunda Rodada de Licitação. 
Tabela 1- Resultado das Rodadas de Licitações de blocos para exploração e produção de petróleo e gás natural promovidas pela ANP - 1999-2013.

\begin{tabular}{|c|c|c|c|c|c|c|c|c|c|c|c|}
\hline \multirow{3}{*}{ Rodadas de licita ção } & \multicolumn{11}{|c|}{ Rodadas } \\
\hline & $\mathbf{1}^{\mathrm{a}}$ & $2^{\mathrm{a}}$ & $3^{\mathrm{a}}$ & $4^{a}$ & $5^{a}$ & $6^{a}$ & $7^{\mathrm{a}}$ & $9^{\varepsilon}$ & $10^{\varepsilon}$ & $11^{\mathrm{a}}$ & $12^{\mathrm{a}}$ \\
\hline & 1999 & 2000 & 2001 & 2002 & 2003 & 2004 & 2005 & 2007 & 2008 & 2013 & 2013 \\
\hline Bacias sedimentares & 8 & 9 & 12 & 18 & 9 & 12 & 14 & 9 & 7 & 11 & 8 \\
\hline Blocos ofertados & 27 & 23 & 53 & 54 & 908 & 913 & 1.134 & 271 & 130 & 289 & 240 \\
\hline Blocos arremat ados & 12 & 21 & 34 & 21 & 101 & 154 & 251 & 117 & 54 & 142 & 72 \\
\hline $\begin{array}{l}\text { Blocos onshore } \\
\text { arrematados } \\
\end{array}$ & - & 9 & 7 & 10 & 20 & 89 & 210 & 65 & 54 & 87 & 72 \\
\hline \begin{tabular}{|l} 
Blocos offshore \\
arrematados \\
\end{tabular} & 12 & 12 & 27 & 11 & 81 & 65 & 41 & 52 & - & 55 & - \\
\hline Blocos concedidos & 12 & 21 & 34 & 21 & 101 & 154 & 242 & 108 & 40 & 120 & \\
\hline $\begin{array}{l}\text { Blocos } \\
\text { arrematados/blocos } \\
\text { ofertados }\end{array}$ & $44 \%$ & $91 \%$ & $64 \%$ & $39 \%$ & $11 \%$ & $17 \%$ & $22 \%$ & $43 \%$ & $42 \%$ & $49 \%$ & $30 \%$ \\
\hline $\begin{array}{l}\text { Blocos } \\
\text { conc edid os b bcos } \\
\text { ofertados }\end{array}$ & $44 \%$ & $91 \%$ & $64 \%$ & $39 \%$ & $11 \%$ & $17 \%$ & $21 \%$ & $40 \%$ & $31 \%$ & $42 \%$ & \\
\hline Área ofe itada $\left(\mathbf{k m}^{2}\right)$ & 132.178 & 59.271 & 89.823 & 144.106 & 162.392 & 202.739 & 397.600 & 73.079 & 70.371 & 155.813 & 163.917 \\
\hline Área arrema tada $\left(\mathbf{k m}^{2}\right)$ & 54.660 & 48.074 & 48.629 & 25.289 & 21.951 & 39.657 & 194.651 & 45.614 & 48.030 & 100.372 & 47.428 \\
\hline $\begin{array}{l}\text { Área onshore } \\
\operatorname{arrematada}\left(\mathbf{k m} \quad{ }^{2}\right)\end{array}$ & - & 10.227 & 2.363 & 10.620 & 697 & 2.846 & 186.916 & 32.195 & 48.030 & 64.998 & 47.428 \\
\hline $\begin{array}{l}\text { Área off shore } \\
\text { arrematada }\left(\mathbf{k m} \quad{ }^{2}\right)\end{array}$ & 54.660 & 37.847 & 46.266 & 14.669 & 21.951 & 36.811 & 7.735 & 13.419 & - & 35.374 & \\
\hline Área c oncedida $\left(\mathbf{k m}^{2}\right)$ & 54.660 & 48.074 & 48.629 & 25.289 & 21.951 & 39.657 & 171.007 & 45.329 & 44.954 & 61.259 & \\
\hline Área onshore & - & 10.227 & 2.363 & 10.620 & 697 & 2.846 & 163.272 & 31.910 & 44.954 & 29.085 & - \\
\hline Área off shore & 54.660 & 37.847 & 46.266 & 14.669 & 21.254 & 36.811 & 7.735 & 13.419 & - & 32.173 & - \\
\hline $\begin{array}{l}\text { Área a rrema tada/área } \\
\text { ofertada }\end{array}$ & $41 \%$ & $81 \%$ & $54 \%$ & $18 \%$ & $14 \%$ & $20 \%$ & $49 \%$ & $62 \%$ & $68 \%$ & $64 \%$ & $29 \%$ \\
\hline $\begin{array}{l}\text { Área concedida/área } \\
\text { ofertada }\end{array}$ & $41 \%$ & $81 \%$ & $54 \%$ & $18 \%$ & $14 \%$ & $20 \%$ & $43 \%$ & $62 \%$ & $64 \%$ & $39 \%$ & \\
\hline $\begin{array}{l}\text { Emp re sas que } \\
\text { manife staram }\end{array}$ & 58 & 49 & 46 & 35 & 18 & 30 & 52 & 74 & 52 & 72 & 26 \\
\hline $\begin{array}{l}\text { Emp re sas que pagar am } \\
\text { a taxa de p articipação } \\
\end{array}$ & 42 & 48 & 44 & 33 & 14 & 27 & 45 & 66 & 43 & 68 & 25 \\
\hline Emp re sas habilit adas ${ }^{2}$ & 38 & 44 & 42 & 29 & 12 & 24 & 44 & 61 & 40 & 64 & 21 \\
\hline $\begin{array}{l}\text { Emp re sas habilit adas } \\
\text { nacionais }\end{array}$ & 3 & 4 & 5 & 4 & 3 & 8 & 19 & 30 & 24 & 17 & 10 \\
\hline $\begin{array}{l}\text { Emp re sas habilit adas } \\
\text { estrangeiras }\end{array}$ & 35 & 40 & 37 & 25 & 9 & 16 & 25 & 31 & 16 & 47 & 11 \\
\hline Emp re sas ofert antes & 14 & 27 & 26 & 17 & 6 & 21 & 32 & 42 & 23 & 39 & 12 \\
\hline $\begin{array}{l}\text { Emp re sas ofert antes } \\
\text { nacionais }\end{array}$ & 1 & 4 & 4 & 4 & 2 & 7 & 14 & 25 & 18 & 12 & 8 \\
\hline $\begin{array}{l}\text { Emp re sas ofert antes } \\
\text { estrangeiras }\end{array}$ & 13 & 23 & 22 & 13 & 4 & 14 & 18 & 17 & 5 & 27 & 4 \\
\hline Emp resas vencedoras & 11 & 16 & 22 & 14 & 6 & 19 & 30 & 36 & 17 & 30 & 12 \\
\hline $\begin{array}{l}\text { Emp re sas vencedoras } \\
\text { nacionais }\end{array}$ & 1 & 4 & 4 & 4 & 2 & 7 & 14 & 20 & 12 & 12 & 8 \\
\hline $\begin{array}{l}\text { Emp re sas vencedoras } \\
\text { estrangeiras }\end{array}$ & 10 & 12 & 18 & 10 & 4 & 12 & 16 & 16 & 5 & 18 & 4 \\
\hline Novos ope radores & 6 & 6 & 8 & 5 & 1 & 1 & 6 & 11 & 2 & 6 & 1 \\
\hline $\begin{array}{l}\text { Cont eúdo local mé di o- } \\
\text { et apa de exploração }\end{array}$ & $25,0 \%$ & $42,0 \%$ & $28,0 \%$ & $39,0 \%$ & $78,8 \%$ & $85,7 \%$ & $74,0 \%$ & $68,9 \%$ & $79,0 \%$ & $61,5 \%$ & $72,6 \%$ \\
\hline $\begin{array}{l}\text { Cont eúdo local mé di o- } \\
\text { etapa de }\end{array}$ & $27,0 \%$ & $48,0 \%$ & $40,0 \%$ & $54,0 \%$ & $85,6 \%$ & $88,8 \%$ & $81,0 \%$ & $76,5 \%$ & $84,0 \%$ & $75,6 \%$ & $84,5 \%$ \\
\hline $\begin{array}{l}\text { Bônus de assinat ura } \\
\text { (milhões R\$) }\end{array}$ & 322 & 468 & 595 & 92 & 27 & 665 & 1.086 & 2.109 & 89 & 2.823 & 165 \\
\hline $\begin{array}{l}\text { Bônus de assinat ura } \\
\text { arrecadado (milhões }\end{array}$ & 322 & 468 & 595 & 92 & 27 & 665 & 1.085 & 2.102 & 80 & 2.480 & \\
\hline $\operatorname{PEM}^{3}$ (UT) & N.A. & N.A & N.A. & N.A. & 33.671 & 131.137 & 195.741 & 169.436 & 128.707 & 400.088 & 129.761 \\
\hline $\begin{array}{l}\text { PEM }^{3} \text { (UT) após } \\
\text { assinat ura }\end{array}$ & N.A. & N.A & N.A. & N.A. & 33.671 & 131.137 & 162.591 & 158.036 & 100.101 & 236.060 & \\
\hline PEM (mihões R\$) & N.A. & N.A & N.A. & N.A. & 364 & 2.047 & 1.797 & 1.367 & 611 & 6.902 & 504 \\
\hline $\begin{array}{l}\text { PEM (milhões R\$) após } \\
\text { assinat ura }\end{array}$ & N.A. & N.A & N.A. & N.A. & 364 & 2.047 & 1.698 & 1.333 & 554 & 5.800 & \\
\hline
\end{tabular}

Fonte: Anual Est atístico Brasileiro do Petróleo, Gás Naturale Bioc ombustíve is - ANP (2014).

[SYN]THESIS, Rio de Janeiro, vol.8, nº 1, 2015, p. 21 - 38

Cadernos do Centro de Ciências Sociais da Universidade do Estado do Rio de Janeiro 
Notas: ${ }^{1}$ Foram consideradoS apenas os dados da rodada de blocos com risco exploratório.

${ }^{2}$ Considera-se habilitada a empresa que cumpriu todos os requisitos previstos no edital de licitações (manifestações de interesse, pagamento da(s) taxa(s) de participação e qualificação). Para apresentar oferta(s) no dia de licitação, a empresa habilitada deve fornecer à ANP garantia(s) de oferta nos termos previstos no edital de licitações.

${ }^{3}$ PEM - Programa Exploratório Mínimo expressa em Unidades de Trabalho.

Nesse contexto, cabe frisar alguns detalhes sobre o conteúdo local e o PEM. A regra de conteúdo local pode encarecer a produção causando a sua ineficiência, visto que a empresa concessionária deve assumir a responsabilidade de comprar no mercado nacional um insumo que pode ter um preço mais baixo no mercado internacional, reduzindo a competitividade do setor. No caso do PEM, as informações sobre a melhor forma de exploração dos campos são obtidas apenas após o início do processo de exploração, devido às peculiaridades do local que não são observadas ex ante. Sendo assim, torna-se importante avaliar a substituição de tais critérios por percentuais nos royalties ou participações especiais (que levam em consideração a receita e o custo), beneficiando a divisão dos riscos do empreendimento e constituindo um contrato de incentivo eficiente (MATTOS, 2008).

Segundo Matoso (2009), a presença dominante da Petrobras em todas as áreas da cadeia produtiva de petróleo e gás natural faz com que ela seja o principal player desse mercado, sendo a grande vencedora de todas as rodadas de licitações. Dos 803 blocos ofertados com lances, durante as dez primeiras rodadas, a empresa estatal participou de 465 delas, saindo como vencedora de 403. Esse resultado é decorrente do conhecimento técnico e operacional da Petrobras, além da sua infraestrutura, que possibilita a empresa ser mais competitiva, ter ganhos de escala e reduzir seus custos.

Em maio de 2013, o Brasil retomou as rodadas de licitações para exploração e produção de petróleo e gás natural, realizando a décima-primeira rodada que teve recorde em arrecadação de bônus de assinatura e compromissos com o PEM, sob o regime de concessão. Um total de 30 empresas, sendo que 18 delas estrangeiras, foram vencedoras de um número bastante expressivo de blocos licitados. A retomada das rodadas de licitação, abrindo a margem equatorial, o pré-sal e a prospecção de gás em terra em imensas extensões territoriais demonstra a dimensão do potencial nacional. Todavia, cabe ressaltar que houve uma interrupção das rodadas, durante aproximadamente cinco anos, causando instabilidade e atraso para o setor petrolífero, que perdeu a oportunidade de ter explorado melhor as suas reservas e atrair investimentos. Ademais, deixou de arrecadar bilhões em bônus de assinatura e prejudicou o crescimento da produção para os próximos anos, visto que a atividade de exploração de petróleo tem alto risco e precisa de um longo período para maturação dos investimentos e concretização da fase de produção.

É importante para o Brasil dar continuidade às Rodadas de Licitação para conservar o seu esforço exploratório e ampliar as suas reservas de petróleo. Com este intuito, a décima-segunda rodada de licitação - sob o regime de concessão - aconteceu em novembro de 2013. Com foco na exploração de gás natural em terra, dos 240 blocos ofertados apenas 72 áreas foram arrematadas por doze empresas. APetrobras foi a grande vencedora, levando quarenta e nove blocos (sendo vinte e sete blocos sozinha e vinte e dois blocos em parceria), arrecadando mais de $70 \%$ dos bônus de assinatura.

Analisando as regras de licitação para a extração de petróleo e gás à luz da teoria dos leilões observa-se que competir pelo direito de explorar um campo com uma empresa com as dimensões da Petrobras não é uma tarefa simples, visto que a estatal vem lidando com pesquisas no país por vários anos, tendo predomínio das atividades offshore (produção em mar). Estas características provocam grande assimetria informacional entre os licitantes. Assim, sob a regra de leilão selado de primeiro preço vencer um leilão concorrendo com a Petrobras é quase certeza de ter incorrido em um erro de análise, mostrando que o vencedor foi impreciso na sua avaliação. Além disso, a Petrobras aplica vultosos recursos financeiros e alta tecnologia, o que, juntamente com a sua capacidade de fazer análises exatas sobre os poços exploratórios, faz com que os participantes tenham 
mais cautela em seus lances. Este fato pode ser demonstrado através da Tabela 1 , em que há uma grande quantidade de blocos sem lance, sobretudo da quinta à sétima rodada.

O modelo de leilão de primeiro preço com envelope selado inviabiliza os licitantes de obterem sinais acerca do verdadeiro valor das áreas exploratórias, quando eles não têm a capacidade de observar as ofertas dos outros participantes. Dessa forma, o modelo adotado minimizou o risco de conluio, porém maximizou o problema da "maldição do vencedor", tornando todos os participantes, com exceção da Petrobras, mais prudentes. Em síntese, as implicações deste tipo de leilão em um ambiente de assimetria de informações entre os participantes podem gerar efeitos insatisfatórios, pois tais assimetrias afetam o comportamento estratégico dos jogadores. Sendo assim, ao contrário do objetivo inicial de determinar maior nível de eficiência e arrecadar maiores receitas, os leilões de primeiro preço selado com forte assimetria de informação podem, ao invés de promover mais concorrência, resultar em menos competição, pois o elevado sucesso da estatal, em todos os leilões realizados, gera retração dos grupos privados em entrar na disputa sem associação com este grande player do setor petrolífero (BRAGANÇA; SALGADO, 2012).

\section{O Regime de Partilla de Produção 4}

A descoberta das jazidas do pré-sal constituiu um novo marco regulatório para a indústria nacional de petróleo e gás natural, trazendo novas dimensões para o país em relação ao potencial e a participação no mercado internacional de petróleo. Desse modo, a promulgação da Lei ${ }^{\circ}$ 12.351/10 foi decisiva para a existência de três modelos de contratação para a realização das atividades de exploração e produção das reservas de petróleo e gás natural no país:

1) regime de partilha de produção: válido tanto para o polígono do pré-sal quanto para as áreas estratégicas, que são caracterizadas pelo baixo risco para exploração e pelo alto potencial para produção;

2) regime de concessão: permanece em vigor nas demais áreas sob a égide da Lei do Petróleo;

3) regime de cessão onerosa.
A principal característica do novo modelo é garantir para o Brasil a maior parcela do petróleo e do gás produzido, apropriando, para o país, uma parcela significativa da valorização do petróleo. O regime de partilha de produção é uma modalidade de contrato que considera as atividades de exploração e produção de petróleo como sendo estratégicas, no sentido de assegurar ao Estado maior controle sobre as atividades do setor petrolífero. Desse modo, a escolha do modelo para a área do pré-sal foi justificada pelo risco exploratório extremamente baixo da região, sendo constatado devido ao excelente desempenho das perfurações realizadas e no volume potencial dos reservatórios encontrados.

A nova Lei ${ }^{\circ}$ 12.351/10 instituiu regras específicas para o modelo de partilha, criou o Fundo Social (com o objetivo de maximizar os benefícios das receitas provenientes das atividades petrolíferas na camada do pré-sal e em áreas estratégicas, administrando os recursos de modo a investir em programas e projetos de desenvolvimento social, regional e de combate à pobreza) e alterou os dispositivos da Lei $n^{\circ} 9.478 /$ 1997, definindo o contrato de partilha de produção como:

\footnotetext{
Regime de exploração e produção de petróleo, de gás natural e de outros hidrocarbonetos fluidos no qual o contratado exerce, por sua conta e risco, as atividades de exploração, avaliação, desenvolvimento e produção e, em caso de descoberta comercial, adquire o direito à apropriação do custo em óleo, do volume da produção correspondente aos royalties devidos, bem como de parcela do excedente em óleo, na proporção, condições e prazos estabelecidos em contrato (BRASIL, 2010, ART $2^{\circ}$, inciso I).
}

Como citado na Lei, o Estado é o proprietário do petróleo produzido, e somente parte do que for explorado será entregue à empresa contratada, em contrapartida às atividades realizadas e ao risco da exploração e produção de hidrocarbonetos. As peculiaridades e as características próprias do setor petrolífero abrangem vários aspectos como a geometria das rochas, os riscos geológicos e a volatividade do preço do óleo. 
Na partilha de produção, os riscos das atividades são assumidos pelos contratados, que serão restituídos apenas se fizerem descobertas comerciais. Esse pagamento é feito com o custo em óleo (cost oil), em valor suficiente para compensar as despesas da(s) empresa(s) contratada(s). O restante da produção, o excedente em óleo (profit oil), é repartido entre a União e a(s) contratada(s). Assim, as especificidades relativas ao modelo e às fases cost oil e profit oil exercem grande influência nas receitas futuras percebidas pela União e contratantes. O contrato definirá as regras e os prazos para a repartição do excedente em óleo, podendo incluir critérios relacionados à eficiência econômica, à rentabilidade, ao volume de produção e à variação do preço do petróleo e do gás natural (art. 29 $9^{\circ}$, inciso VII da referida lei).

Finalmente, cabe citar duas leis que antecederam a Lei 12.351/10. A primeira, Lei $\mathrm{n}^{\circ} 12.304 / 10$, autorizou a União, dispensada de licitação, a ceder onerosamente à Petrobras até cinco bilhões de barris de petróleo situados no perímetro do pré-sal. A segunda, Lei n ${ }^{\circ} 12.304 / 10$, possibilitou a criação da Empresa Brasileira de Administração de Petróleo e Gás Natural - Pré-Sal Petróleo S.A. (PPSA) para conduzir os contratos sob o modelo de partilha de produção, celebrados pelo Ministério de Minas e Energia (MME), como também gerir os contratos para a comercialização de petróleo e gás natural da União.

\subsection{LEILÃO DE LIBRA: PRIMEIRA RODADA DE LICITAÇÃo SOB O REGIME DE PARTILHA DE PRODUÇÃO}

O leilão de Libra - realizado no dia 21 de outubro de 2013 - foi a maior licitação da história do Brasil e a primeira grande oportunidade de testar o novo marco regulatório para exploração de petróleo e gás natural, atendendo a novas regras do contrato de partilha de produção. A área ofertada nesta licitação foi selecionada na Bacia de Campos em área contendo a estrutura do polígono do pré-sal.

A área de Libra é a maior reserva do pré-sal. De acordo com a ANP (2013), as reservas nacionais de petróleo devem dobrar, estimando-se que o volume de óleo recuperável varie de 8 a 12 bilhões de barris.
Adicionalmente, há uma estimativa de que o campo de Libra consiga produzir 1,4 milhão de barris por dia. Além disso, espera-se que as reservas de gás também sejam duplicadas.

$\mathrm{O}$ arcabouço institucional que regeu o leilão foi o seguinte:

a) taxa de participação mínima de $\mathrm{R} \$$ 2.067.400,00, sendo obrigatório e individual para cada empresa licitante;

b) a estatal PPSA tem a competência de gerir todos os contratos de partilha, representando a União em todos os consórcios;

c) obrigatoriedade de uma única empresa operadora para todos os contratos realizados, no caso a Petrobras, com uma participação mínima de 30\%;

d) a empresa vencedora deverá reverter o maior percentual excedente do petróleo à União, sendo o percentual mínimo de $41,65 \%$ o único critério de concorrência adotado;

e) o bônus de assinatura a ser pago será no valor de $\mathrm{R} \$ 15$ bilhões;

f) o contrato de partilha terá validade de trinta e cinco anos, sendo quatro anos para exploração e o restante para desenvolvimento e produção.

Nesse contexto, devido ao fato de a área de Libra ser promissora e ter um enorme potencial de produção, havia grande expectativa por parte do governo em relação ao número de empresas que iriam participar da licitação, esperando-se aproximadamente quarenta empresas e a formação de alguns consórcios para disputar com a Petrobras. Porém, o leilão reuniu menos empresas do que previsto inicialmente, com a ausência notória de grandes players da indústria de petróleo internacional, como a Chevron, a Exxon Mobil e as britânicas BP e BG. Onze empresas estavam habilitadas para o certame, mas somente cinco apresentaram proposta. Após o resultado, a Petrobras ficou com uma participação de $40 \%$ (30\% obrigatórios mais $10 \%$ de lance na proposta) e as outras quatro empresas, dentre elas duas estatais chinesas (CNPC International Ltd e CNOOC International Limited), ficaram com o restante $(60 \%)$, conforme mostra a Tabela 2. 
Tabela 2 - Lances dados por cada empresa na Primeira Licitação de Partilha de Produção

\begin{tabular}{lc|c}
\hline Nome da Empresa & Participação (\%) & Excedente em Óleo para a União (\%) \\
\hline Petróleo Brasileiro S.A. & 10 & \\
Shell Brasil Petróleo Ltda. & 20 & $41,65 \%$ \\
Total S.A. & 20 & \\
CNPC International Ltd. & 10 & \\
CNOOC International Limited & 10 & \\
\hline
\end{tabular}

Fonte: Elaboração própria a partir de dados do Brasil-Rounds - Licitações de Petróleo e Gás (2013).

Dessa forma, cabe ressaltar que o cenário mais otimista não se confirmou, ou seja, o modelo proposto não foi capaz de promover a concorrência, pois apenas um consórcio - formado pelas empresas Petróleo Brasileiro S.A., Shell Brasil Petróleo Ltda., Total S.A., CNPC International Ltd. e CNOOC International Limited - ofereceu proposta, pagando o percentual mínimo fixado pelo governo. Sendo assim, vários fatores contribuíram para a baixa adesão por parte das empresas.

Em primeiro lugar, o excesso de intervencionismo governamental aumenta o risco regulatório, ainda mais com a criação de uma nova estatal - PPSA - que tem poder de veto. É como se o governo tivesse criado uma nova estatal para resolver os problemas de assimetria de informação do setor. Sendo assim, as empresas estrangeiras ficaram com receio de que os direitos garantidos ao governo pudessem definir o ritmo dos investimentos e as decisões de desenvolvimento.

Em segundo lugar, a atuação da Petrobras como operadora única e com o mínimo de participação de $30 \%$, determinado por lei, faz com que as outras empresas percam a autonomia de atuar como operadoras.

Por último, a exigência de um bônus de assinatura tão alto contribuiu para que as empresas privadas perdessem o interesse no leilão, visto que elas estavam mais interessadas em obter retornos em um horizonte mais curto, diferentemente das duas estatais chinesas, cujo principal objetivo é estratégico, ou seja, ter acesso às reservas de petróleo.

A primeira rodada de licitação do polígono do présal arrecadou, segundo a ANP (2013), quase o dobro do valor pago em todas as rodadas já realizadas no Brasil. A Petrobras terá que desembolsar $\mathrm{R} \$ 6$ bilhões dos R 15 bilhões de bônus de assinatura, valor referente à sua parcela de $40 \%$ sobre o bônus.

Como a Petrobras ficou com uma parcela considerável do consórcio vencedor, uma questão que se coloca em foco é a sua capacidade técnica, administrativa e financeira em realizar investimentos dentro dos prazos estipulados para que a área de Libra alcance o seu máximo de produção nos próximos anos.

O regime de partilha de produção adotado pelo governo para explorar o polígono do pré-sal não foi eficiente, pois somente um consórcio se formou e a falta de concorrência fez com que este ofertasse o mínimo de óleo produzido (41,65\%), não gerando um excedente em óleo satisfatório para a União. Além disso, o fato dos leilões terem sido suspensos por cinco anos contribuiu para que a bacia de Libra não fosse mais tão atrativa nesse momento, pois os prazos para produção na cadeia do petróleo são longos, podendo levar pelo menos cinco anos para começar a produção, que depende da geologia do local e dos investimentos realizados.

Contudo, o governo precisa rever o modelo de contrato de partilha, pois a sua governança se mostrou 
bastante complexa, visto que seria mais fácil ter continuado com o bem sucedido modelo de concessão, não alterando as suas diretrizes. Uma melhoria que o governo poderia realizar é aumentar as participações especiais para obter um lucro maior. Ademais, o governo também precisa focar na questão da fiscalização e dedução dos custos de operação, para não incorrer em problemas futuros.

\section{Análise dos Resultados e Sugestões de Políticas ECONÔMICAS}

O modelo de partilha de produção adotado no Brasil é complexo e precisa de uma avaliação minuciosa. Assegurar participação mínima de 30\% para a Petrobras comprometeu significativamente os incentivos para a formação de consórcios e o desempenho do leilão, proporcionando um resultado ineficiente (em termos de concorrência) e um retorno insatisfatório para o governo (que atua como leiloeiro e participante, através da Petrobras), que entregou a área licitada pela oferta mínima (41,65\%). A questão da falta de incentivo à concorrência fica claramente explícita quando observamos a receptividade do mercado em relação ao leilão de Libra que foi bem diferente e inferior se comparado à décima-primeira rodada de licitação, que teve como mérito estimular a competitividade atraindo um número considerável de participantes, inclusive empresas estrangeiras.

Esta participação mínima obrigatória da estatal gera maior informação entre as empresas e, provavelmente e acentua o problema da "maldição do vencedor". Considerando que a Petrobras é o agente melhor informado e rejeitando a possibilidade de restrições orçamentárias da incumbente, observa-se que o governo tem o incentivo de ampliar a sua participação para além do percentual mínimo vigorado na lei, em blocos em que a certeza de rentabilidade é alta. Assim, fica claro que as empresas reduzirão a sua participação em leilões nos quais a Petrobras tenha uma participação mínima de 30\%, reconhecendo-os como mais arriscados. Com isso, a concorrência no setor ficará prejudicada.

Portanto, torna-se extremamente necessário uma análise criteriosa do atual modelo de exploração de petróleo e gás natural, formando um arcabouço regulatório eficiente e garantindo segurança jurídica aos investidores e licitantes.

O modelo de concessão beneficia a identificação e a punição do cartel, devido à simultaneidade dentro do bloco e a sequencialidade entre os blocos, como também agrava o resultado da chamada "maldição do vencedor", em função da adoção do leilão selado de primeiro preço.

Segundo Bragança e Salgado (2012, p.23), alguns problemas derivados da presença de conluio nos leilões sequenciais (cada lote é negociado independentemente dos demais) podem ser mitigados de três maneiras: i) usando modelos de lotes para inibir a divisão do mercado; ii) estabelecendo regras (inclusive com imposição de custo) que proíbam a retirada das propostas e seus valores, prejudicando acordos entre os licitantes; e iii) proibindo alterações de preços propostos que implicam em vencedores ilegítimos. Além disso, a imposição de anonimato aos licitantes e/ou aos lances evita o conhecimento prévio dos blocos, por parte dos participantes, antes do resultado do leilão.

A "maldição do vencedor" representa um grande problema para o novo marco regulatório responsável pelo polígono do pré-sal, posto que a participação da Petrobras seja instituída de forma política, tendo como justificativa razões estratégicas. Este problema pode ser solucionado através da adoção de um desenho de leilão híbrido, que possibilita a aprendizagem e reduz a assimetria de informação (Bragança e Salgado, 2012).

Vale destacar o problema da "maldição do vencedor" e a eficiência relativa da Petrobras, uma vez que a estatal é notoriamente o grande player do setor de petróleo, tendo maior conhecimento técnico e tácito. Durante os leilões realizados sob o regime de concessão, nota-se (isto pode ser identificado na Tabela 1) que há um grande número de lotes onde não houve disputa, ou seja, não foi arrematado, o que pode sinalizar um efeito da maldição do vencedor, que acaba por desincentivar os licitantes a 
participarem da disputa de um determinado lote onde a assimetria de informação seja mais elevada.

$\mathrm{Na}$ ausência de conhecimento empírico sobre os resultados de desenho de leilões nas condições estabelecidas atualmente no Brasil - convívio com três sistemas de contratação das atividades de exploração e produção de petróleo e gás natural: regime de partilha, regime de concessão e regime de cessão onerosa - torna-se imprescindível o estudo e a aplicação da economia experimental para tratar as questões levantadas anteriormente e trazer respostas sobre quais os mecanismos de leilões seriam mais apropriados para serem implementados no setor petrolífero nacional, evidenciando quais modelos de leilão são capazes de resolver o problema recorrente da "maldição do vencedor".

Cabe enfatizar que as evidências teóricas e empíricas da literatura econômica, em relação à teoria dos leilões, levam-nos a acreditar na sua eficiência em contribuir para solucionar os problemas relativos ao desenho de leilões adotados no Brasil. Dessa forma, Mattos (2008) identificou algumas das características dos leilões que são mais recomendáveis para serem aplicadas no setor de petróleo nacional, tais como:

i) fazer um leilão ascendente e simultâneo (os objetos são vendidos ao mesmo tempo), especialmente onde a ameaça de cartelização for menor;

ii) introduzir o leilão híbrido com base no modelo Anglo-Holandês;

iii) introduzir o modelo híbrido do tipo "clockproxy", especialmente interessante em casos de áreas muito complementares ${ }^{4}$.

A ideia é sugerir que se utilizem algumas das características da teoria dos leilões nas próximas licitações realizadas no Brasil. Não há como indicar um modelo fechado, pois os estudos em teoria dos leilões ainda são muito recentes. O que podemos fazer é analisar os modelos existentes, sugerindo outros modelos ou combinações destes e tendo em vista a complexidade da elaboração das regras de um determinado leilão, pois os participantes levam em consideração as suas estimativas e o comportamento dos seus oponentes. Uma alternativa plausível seria poder testar alguns tipos de leilões em laboratório para corrigir seus erros e fazer ajustes, a fim de garantir eficiência econômica e gerar mais rendimentos para o governo. Ademais, este modelo deve desfavorecer a formação de conluio e promover a concorrência.

A premissa de usar experimentos econômicos no setor petróleo consiste em testar vários modelos (desenho de mecanismos), analisar dados, organizar informações, verificar falhas e melhorar o design. As experiências laboratoriais são uma ferramenta de análise econômica empírica que ajuda a tomar boas decisões, evitando desperdiçar recursos implementando métodos ineficientes. De outra forma, para não incorrer em problemas de planejamento e execução, é necessário primeiro testar e errar no laboratório para depois pôr em prática.

Polydoro (2014) definiu como poderia ser um leilão experimental ou um experimento econômico. Primeiramente, um grupo de participantes (alunos de graduação e pós-graduação) é escolhido de forma anônima para integrar uma sessão experimental. Depois, recebem explicações sobre as regras do leilão e realizam tarefas-teste a fim de validar o seu entendimento, sendo que o resultado não influencia no pagamento ao final da sessão. A proposta dessa metodologia experimental é que remunerando os participantes pelo sucesso do leilão, eles são incentivados a levar a sério as regras do leilão e prestar atenção no comportamento dos outros participantes. Sendo assim, o desempenho dos participantes determina observações independentes em relação ao resultado do experimento em termos de eficiência, receita para o leiloeiro e lucro dos participantes. Devido à flexibilidade deste ambiente experimental é possível conduzir vários tipos de experimentos, podendo ao final da sessão, usar-se um questionário para auxiliar na clareza das regras e validação dos resultados.

Klemperer (2004) descreve o sucesso dos leilões de espectro de terceira geração $(3 \mathrm{G})$ realizados na Inglaterra, que utilizam experimentos em laboratório para testar o melhor desenho de leilões antes de aplicálos no mercado, tendo a possibilidade de avaliar os 
conceitos da teoria dos leilões e corrigir os seus erros. Este leilão favoreceu a entrada de novos participantes, promoveu a concorrência e superestimou os resultados esperados. Além disso, reduziu a ocorrência de conluio e prática predatória.

A partir da experiência abordada observamos que a aplicação de leilões experimentais era o que poderia ter sido realizado no Brasil antes do leilão do pré-sal, para evitar o resultado apresentado: um leilão formado por apenas um consórcio ofertando o valor mínimo, como também não conseguiu aumentar o número de licitantes e a competitividade entre as empresas participantes. Entretanto, mesmo que tivessem sido realizados experimentos, não haveria certeza de qual seria o melhor desenho de leilões a escolher, porque a economia não é uma ciência exata, pois envolve escolha de pessoas em ambiente de incertezas. No entanto, a possibilidade de analisar, estudar profundamente e testar algumas questões econômicas, antes de colocá-las em prática, contribui positivamente para alcançar um resultado mais eficiente e satisfatório - que no caso de um leilão, como os promovidos pela ANP, é maximizar a receita e explorar o maior número de blocos possíveis.

Dessa forma, a teoria dos leilões e as ferramentas de economia experimental poderiam ser amplamente utilizadas em ambiente de laboratório, promovendo maior diálogo entre os pesquisadores e os formuladores de políticas públicas, incentivando, assim, a aplicação e a prática da realização de leilões experimentais no Brasil. É possível que as regularidades empíricas provenientes dos estudos laboratoriais possam contribuir positivamente com boas recomendações de política econômica.

\section{Conclusão}

A descoberta da fronteira exploratória do pré-sal representa uma nova fase para o setor de petróleo nacional, devido a sua potencialidade e menor risco exploratório. Mesmo antes de ter certeza da viabilidade das reservas, o governo promoveu várias mudanças no aparato legal desta indústria, causando instabilidade no setor. A mudança no marco regulatório, ou seja, a alteração do regime de concessão pelo regime de partilha de produção, que apresenta vários erros na sua estrutura e formulação, não foi uma boa escolha estratégica. O grande problema é o regime de partilha adotado no Brasil, em que se atribuem maiores poderes comerciais à Petrobras. O novo arcabouço regulatório fragiliza o setor petrolífero ao concentrar toda a operação na Petrobras e todo o planejamento operacional na PPSA. Assim, eventuais problemas na economia não poderão ser mitigados por outras empresas.

Abordagens baseadas na Teoria dos Leilões têm sido amplamente estudadas e desenvolvidas. Assim, os leilões são as principais ferramentas para atribuir às áreas de petróleo e gás natural as empresas mais eficientes, entretanto a sua formatação correta é determinante para alcançar tal propósito. Nos leilões promovidos pela ANP, o problema da "maldição do vencedor" deveria ser o aspecto mais importante para a elaboração das regras, o que está em conflito com o atual modelo de leilão selado de primeiro preço.

Mediante um cenário de grandes incertezas e informação assimétrica impõe-se uma avaliação robusta dos mecanismos de leilões para ajudar na condução do novo marco regulatório existente no Brasil, uma vez que o modelo tríplice de contratação das atividades de exploração e produção de petróleo e gás em vigor (regime de concessão, regime de partilha de produção e regime de cessão onerosa), é inusitado e não tem exemplos em outros países.

A primeira rodada de licitação sob o regime de partilha de produção poderia ter gerado um resultado melhor, com maior excedente em óleo para o governo, porém as regras propostas no leilão e a acentuada participação do governo e da Petrobras (ainda mais com uma nova estatal com poder de veto) dificultaram a concorrência, pondo em risco a credibilidade do contrato de partilha. Por isso, os modelos de leilões deveriam ser testado, antes de serem lançados no mercado, através da economia experimental, que pode fornecer, através de testes em laboratório, modelagens mais próximas dos cenários reais.

Dessa forma, para cumprir os objetivos de 
maximização da receita, concessão do maior número possível de blocos leiloados e a promoção de pesquisa e exploração, faz-se necessário o uso dos aspectos fundamentais da teoria dos leilões para gerar eficiência e alcançar os objetivos satisfatoriamente, visto que muitos são os desafios e as promessas que o setor petrolífero oferece, ainda mais que o Brasil perdeu tempo precioso com a interrupção, durante cinco anos, dos leilões para concessão de novas áreas com potencial para exploração. No entanto, cabe ressaltar que no ano de 2013 a ANP realizou três leilões históricos: a décima-primeira rodada de licitação, que foi um sucesso de arrecadação de bônus de assinatura; a décima-segunda rodada de licitação, a primeira a oferecer exclusivamente blocos em terra, com ênfase em gás; e a primeira rodada de licitação do pré-sal. Provavelmente, o sucesso da décima-primeira rodada incentivou o governo a antecipar a licitação de Libra e a décima-segunda rodada com a expectativa de considerável arrecadação de bônus de assinatura.

Finalmente, a partir da análise de todas as questões abordadas tendo como destaques: i) a mudança do marco regulatório devido à descoberta do polígono pré-sal, que acabou suspendendo as rodadas de licitações em outras áreas; ii) o arcabouço regulatório do modelo de partilha, que difere dos padrões internacionais da indústria de petróleo; e iii) os resultados da primeira licitação do pré-sal que não favoreceu a concorrência, a atração de grandes empresas internacionais e ainda arrecadou pelo bloco licitado o valor mínimo determinado pela lei; permanecem alguns questionamentos que precisam ser refletidos e superados, sendo o principal a continuação do modelo de partilha proposto, visto que as atividades de exploração, desenvolvimento e produção do setor petrolífero nacional não podem parar, pelo contrário, precisam aumentar substancialmente a fim de atrair investimentos vultosos e fomentar o crescimento do país. Sendo assim, a teoria dos leilões e a economia experimental são recursos imprescindíveis para minorar os problemas levantados.

Além dos aspectos abordados no decorrer deste artigo, diversos elementos podem ser estudados e aprofundados futuramente, como a introdução de leilões híbridos no modelo de leilão da ANP e a utilização de experimentos econômicos para testar e avaliar a viabilidade dos diferentes desenhos de leilões que podem ser elaborados.

\section{Notas Explicativas}

1 "O termo pré-sal refere-se a um conjunto de rochas localizadas nas porções marinhas de grande parte do litoral brasileiro, com potencial para geração e acúmulo de petróleo. Convencionouse chamar de pré-sal porque forma um intervalo de rochas que se estende por baixo de uma extensa camada de sal, que em certas áreas da costa atinge espessuras de até $2.000 \mathrm{~m}$. O termo pré é utilizado porque, ao longo do tempo, essas rochas foram sendo depositadas antes da camada de sal. A profundidade total dessas rochas, que é a distância entre a superfície do mar e os reservatórios de petróleo abaixo da camada de sal, pode chegar a mais de sete mil metros." (PETROBRÁS, 2013)

${ }^{2} \mathrm{O}$ hidrocarboneto é um composto constituído apenas por carbono e hidrogênio. O petróleo e o gás natural são exemplos de hidrocarbonetos.

${ }^{3}$ Esta seção foi baseada, em grande parte em Bragança e Salgado (2012).

${ }^{4} \mathrm{Na}$ complementaridade, o valor de dois ou mais objetos arrematados em conjunto é maior do que quando arrematados por licitantes diferentes. Cramton (2006 apud Mattos, 2008) aborda que a complementaridade pode ser vista por três formas distintas: i) economias de escala tradicionais, quando ocorre o compartilhamento da mão-de-obra e dos equipamentos para exploração; ii) free-riding, quando os detentores de licenças de áreas próximas aguardam os "vizinhos" começarem a exploração, para avaliar a possibilidade de realização da sua própria pesquisa, e iii) "propriedade fugitiva", quando os lotes localizados em áreas adjacentes acabam extraindo óleo ou gás do mesmo reservatório.

\section{REFERÊNCIAS BIBLIOGRÁFICAS}

AGÊNCIA NACIONAL DO PETRÓLEO, GÁS NATURAL E BIOCOMBUSTÍVEIS. Anuário Estatístico Brasileiro do Petróleo, Gás Natural e Biocombustíveis 2014. Rio de Janeiro: ANP, 2014.

BAZERMAN, M. H.; SAMUELSON, W. F. I Won the Auction but don't Want the Prize. Journal of Conflict Resolution, v. 27, n. 4, p. 618-634, Dec. 1983.

BRAGANÇA, G. G. F. de; SALGADO, L. H. Desenho de Leilões para os Acordos de Partilha na Área do Pré-Sal: Questões em Aberto. Radar: Tecnologia, Produção e Comércio Exterior, Brasília, v. 22, p. 17-24, out. 2012. Disponível em: 
<http://www.ipea.gov.br/portal/images/stories/PDFs/radar/ 121114_radar22.pdf>. Acesso em: nov. 2012.

BRASIL. Lei n ${ }^{\circ}$ 9.478/1997, de 6 de agosto de 1997. Disponível em:<http://www.planalto.gov.br/ccivil_03/leis/19478.htm>.

Lei $n^{\circ} 12.351$, de 22 de dezembro de 2010. Disponível em: <http://www.planalto.gov.br/ccivil_03/_Ato2007-2010/ 2010/Lei/L12351.htm>.

BRASIL-ROUNDS - LICITAÇÕES DE PETRÓLEO E GÁS Disponível em: <www.brasil-rounds.gov.br>. Vários Acessos.

CRAMTON, P. How Best to Auction Oil Rights. Apr. 2006. Mimeografado.

GIAMBIAGI, F. e LUCAS, L. P. Vellozo (Org.). Petróleo: Reforma e Contrareforma do Setor Petrolífero Brasileiro. Rio de Janeiro: Elsevier, 2013.

GOMES, C. J. V. O Marco Regulatório da Prospecção de Petróleo no Brasil: O Regime de Concessão e o Contrato de Partilha de Produção. Brasília: Centro de Estudos da Consultoria do Senado Federal, 2009. (Texto para Discussão $\left.\mathrm{n}^{\circ} 55\right)$.

HENDRICKS, K. e PORTER, R. An Empirical Study of an Auction with Asymmetric Information. American economic review, v. 78, n. 5, p. 865-883, 1988.

HENDRICKS, K.; PINKSE, J.; PORTER, R. H. Empirical Implications of Equilibrium Bidding in First-Price, Symmetric, Common Value Auctions. Review of economic studies, v. 70, p. 115-145, 2003.

KAGEL, J. H., ROTH, A. E. (Ed.) The Handbook of Experimental Economics. Princeton: Princeton University Press, 1995

KLEMPERER, P. Auctions: Theory and Practice. Princeton.: Princeton University Press, 2004.

What Really Matter in Auction Design? Journal Economic Perspectives, England, 2001.

MATOSO, R. S. Leilões de Blocos Exploratórios de Petróleo e Gás no Brasil: 2009. 133 p. Dissertação (Mestrado) Faculdade de Economia e Finanças IBMEC, Rio de Janeiro, 2009.

MATTOS, C. Licitações da ANP, Petrobras e a Maldição do Vencedor. In: SALGADO, L. H; MOTTA, R. S. da (Ed.). Marcos Regulatórios no Brasil: incentivos ao investimento e governança regulatória. Rio de Janeiro: IPEA, 2008. p. 65 97.

MENEZES, F.; MONTEIRO, P. An Introduction to Auction Theory. 1. ed. New York: Oxford University Press, 2004.

MIELNIK, P. Evolução dos Leilões de Exploração e Produção (E\&P) de Petróleo e Gás natural no Brasil. Cadernos FGV Energia, Rio de Janeiro, ano 1, n. 1, p. 12-28, maio 2014.

MINISTÉRIO DE MINAS E ENERGIA. Novo Marco Regulatório: pré-sal e áreas estratégicas. Disponível em: $<$ http://www.mme.gov.br/mme/galerias/arquivos/pre_sal/ marcoregulatorio.pd.f>. Acesso em: 10 set. 2013.

PETROBRAS. Marco Regulatório de Exploração e Produção de Petróleo e Gás: 30 Perguntas e Respostas. Disponível em: <http://fatosedados.blogspetrobras.com.br/wp-content/ uploads/2009/10/Perguntas-e-respostasOTI_FINAL.pdf> . Acesso em: 11 set. 2013.

PIRES, A.; CAMPOS FILHO, L. A Abertura do Setor Petróleo e Gás Natural: retrospectiva e desafios futuros. In: GIAMBIAGI, F. Reformas no Brasil: balanço e agenda. Rio de Janeiro: Nova Fronteira, 2004. p. 409-430.

POLYDORO, A. Introdução à Teoria de Leilões e sua Aplicação aos Leilões de (E\&P). Cadernos FGV Energia, Rio de Janeiro, ano 1, n ${ }^{\circ}$ 1, p. 30-35, maio 2014.

ROTH, A. (1995). Alvin Roth: Introduction to Experimental Economics. In: Kagel e A. Roth 1995.

SAlGADO, L. H. O Regime de Partilha de Produção e o Instituto da Unitização na Indústria de Petróleo e Gás Natural: problemas e soluções. Rio de Janeiro: UERJ, 2011. 19p. Mimeografado.

SMITH, V. L. An Experimental Study of Competitive Market Behavior. The Journal of Political Economy, p.111-137, 1962.

Effect of Market Organization on Competitive Equilibrium. The Quarterly Journal of Economics, v.78, $\mathrm{n}$. 2, p. 181-201, 1964.

TEIXEIRA, M. M. A. Uma Análise Econômica dos Modelos de Contrato de Concessão e Partilha de Produção no Setor Petrolífero no Brasil. 2013. 95f. Dissertação (Mestrado em Ciências Econômicas) - Faculdade deCiências Econômicas, Universidade do Estado do Rio de Janeiro, Rio de Janeiro, 2013.

VANZAN, D. M. O Fenômeno da Maldição do Vencedor em Leilões: um estudo experimental. Rio de Janeiro, 2004. Dissertação (Mestrado em Administração) - Instituto COPPEAD de Administração, Universidade Federal do Rio de Janeiro, Rio de Janeiro, 2004. 